pleted the baseline interview, and $90 \%$ or more of these completed each of the follow up interviews. In the 3724 person-months during which subjects had "outdoor exposure", 155 falls were reported. The incidence rates of indoor and outdoor falls were 21.2 and 20.4 falls per 1000 person-months, respectively. The table shows that the risk factors differed for indoor and outdoor falls. Our results, if confirmed, suggest that indoor and outdoor falls should be studied as separate outcomes. This distinction might eventually prove useful for the design of preventive interventions.
This research was supported by the Fonds de la Recherche en Santé du Québec (grant 158085).

1 Hale WA, Delaney MJ, McGaghie WC. Characteristics and predictors of falls in elderly patients. $\mathcal{f}$ Fam Prac 1992;34:577-81.

2 Tinetti ME. Factors associated with serious injury during falls by ambulatory nursing home residents. $\mathcal{F}$ Am Geriatr Soc 1987;35:644-8.

3 Tinetti ME, Speechley M, Ginter SF. Risk factors for falls among elderly persons living in the community. $N$ Engl $f$ Med 1988:319:1701-7.

4 O'Loughlin J, Robitaille Y, Boivin JF, Suissa S. The incidence of and risk factors for falls and injurious falls among community-dwelling elderly. Am $\mathcal{f}$ Epidemiol 1993;137:342-54.

5 D'Agostino RB, Lee M, Belanger AJ, Cupples LA, Anderson $\mathrm{K}$, Kannel WB. Relation of pooled logistic regression to time dependent Cox regression analysis: The Framingham Heart Study. Stat Med 1990;9:1501-15.

\title{
Remembering fractures: fracture registration and proband recall in southern Sweden
}

\author{
Brynjólfur Jónsson, Per Gärdsell, Olof Johnell, Inga Redlund-Johnell, Ingemar Sernbo
}

This study aimed to examine fracture recall and to compare different sources of information on fracture registration both within the same population and between areas. The study was carried out in southern Sweden. Altogether 782 individuals of both sexes from the city of Malmö, and 486 residents from the nearby rural community of Sjöbo were invited to participate in a population based study. A total of $570(73 \%)$ from Malmö and 391 (80\%) from Sjöbo participated. For all subjects, fracture data were obtained from three different sources - one, the probands' own recollection of previous fracture episodes and the other two, patient records. In addition, the age at the time of fracture and the severity of the trauma that caused the fracture were recorded. Where fractures were sustained and treated elsewhere and were not on our records, records from other hospitals were not studied.

Results: In Malmö, 155 of the subjects had sustained a total of 252 fractures. In Sjöbo, 75 probands had sustained 91 fractures. In Malmö $40 \%$ and in Sjöbo $22 \%$ of the fractures had been forgotten by the probands and were discovered from patient records (figure). In both communities, half of those with fractures not detailed in the records had either been treated elsewhere or had moved to their present residence since their fractures. Almost $40 \%$ of all fractures had been forgotten by the probands: in men $60 \%$ of fractures of the hand and foot and in women $22 \%$ of fractures of the distal end of the radius had been forgotten.

The median time that had elapsed between forgotten fractures and the interview was longer than that for remembered fractures: in Malmö these times were 15 and 9 years, respectively $(p=0.001$, Mann-Whitney) and in Sjöbo, 14 and 9 years, respectively $(p=0.001)$. Fractures caused by more severe trauma were signific- antly more likely to have been forgotten in Malmö - these high energy fractures were more common in men.

Discussion: The data indicate that there will be considerable under-reporting if only one source of information is used in the screening of fractures. The cause of the discrepancy between registration and recall in the two communities may be less accurate registration in Sjöbo because people living in the outskirts of the community might have sought medical care outside of the health district.

In prospective studies, medical records have been found to confirm fracture history in all cases in women, ${ }^{1}$ but over reporting of self reported fractures has been found in $20 \%$ of cases among elderly women. ${ }^{2}$ Even in cross sectional studies similar to ours there was a tendency to over report fractures. ${ }^{3}$ Because the accuracy of a positive fracture history outside the study health districts was not examined, some of the fractures reported but not recorded may be false positives. An alternative explanation might be either better recall in rural probands, who also had fewer fractures, and fewer fractures per fractured individual, ${ }^{4}$ together with possibly more tangible effects of the fractures on the working capacity in a farming population.

Women in this study had forgotten more than one fifth of the fractures of the distal end of the radius. This is in line with the study of Åkeson et al, 5 in which $14 \%$ of 36 women did not remember having sustained a wrist fracture 0-35 (mean 10) years earlier, and additionally $17 \%$ had forgotten which side they had broken.

The time elapsed since the fracture seems to be of importance for recall. In this study the median time elapsed after a remembered fracture was 9 years, whereas it was 14-15 years for 


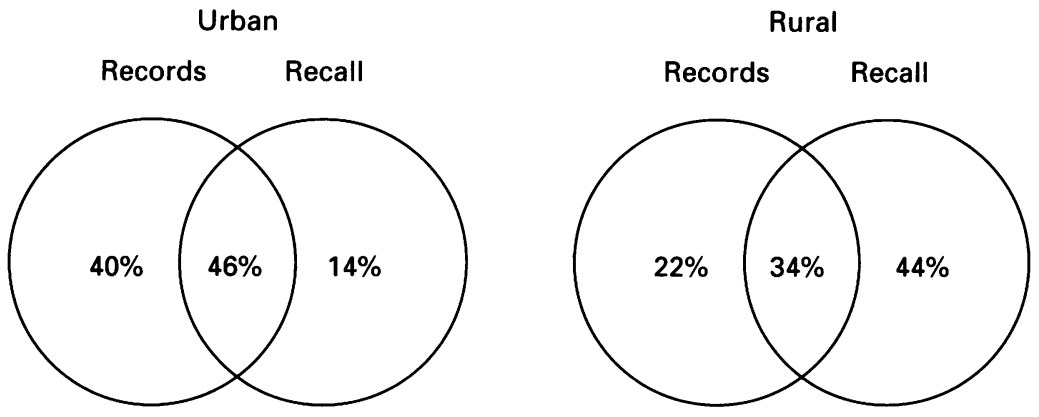

The distribution of information on fractures in responding urban and rural probands. Both sexes from each area are grouped tcgether. The percentage of fractures from each source of information is given. a forgotten fracture. This means that all studies on fracture prevalence must be based on some kind of fracture documentation rather than proband memory only.
Financial support for the study was granted by the Swedish Medical Research Council (project No. -89-27X-07975-03), The Herman Järnhardt, Greta and Johan Koch, Alfred Österlund Foundations; and the donation foundations of the Medical Faculty University of Lund.

1 Colditz GA, Martin P, Stampfer MJ, et al. Validation of questionnaire information on risk factors and disease outcomes in a prospective cohort study of women. $\mathrm{Am} \mathcal{F}$ Epidemiol 1986;123:894-900.

2 Nevitt MC, Cummings SR, Browner WS, Seeley DG, Cauley JA, Vogt TM, Black DM. The accuracy of self-report of fractures in elderly women: evidence from a prospective study. Am ₹ Epidemiol 1992;135:490-9.

3 Bush TL, Miller SR, Golden AL, Hale WE. Self-report and medical record report agreement of selected medical con-
ditions in the elderly. Am $\mathcal{f}$ Public Health 1989;79:1554-6.

4 Jónsson B, Gärdsell P, Johnell O, Redlund-Johnell I, Sernbo I. Differences in fracture pattern between an urban and a I. Differences in fracture pattern between an urban and a
rural population: a comparative population-based study in rural population: a comparative population-based
southern Sweden. Osteoporos Int 1992;2:269-73.

5 Åkesson K, Gärdsell P, Sernbo I, Johnell O, Obrant KJ. Earlier wrist fracture: a confounding factor in distal forearm bone screening. Osteoporos Int 1992;2:201-4.

\section{School injuries in Athens: socioeconomic and family risk factors} Eleni Petridou, Nicoletta Kouri, Dimitrios Trichopoulos, Katharine Revinthi,
Yannis Skalkidis, Donald Tong

Injuries are the main cause of morbidity and mortality in childhood, and there is increasing interest in injuries at school. ${ }^{1-3}$ There is a strong socioeconomic gradient for childhood injuries and deaths. ${ }^{4}$ We have undertaken a case-control study in Athens, Greece, to examine the importance of family and social risk factors for injuries at school - that is, an environment not directly related to home conditions and immediate family supervision. By matching cases and controls on the school we have controlled for the contribution of factors associated with the general school situation.

Methods: Between September 1992 and June 1993 one of us was present for a total of 80 nonconsecutive days at the accident and emergency clinics of one of the two major University Children's Hospitals in Athens. During this period, a total of 101 school children aged 5-14 years, resident in the Athens area, were brought to the clinics for an injury that had taken place at school and was sufficiently serious to require hospital contact. These children's schools were identified and three controls, exactly matched for school, age (single year), and gender, were randomly selected for every injury case from the respective class rosters. A standardised interview form was completed for 404 children by their teachers in collaboration with the children's families, and the variables shown in the table were assessed by modelling through conditional logistic regression. ${ }^{5}$

Results: Of the 101 injuries, 49 took place in playground areas, 39 in classrooms and corridors (mostly during breaks), 10 during sporting activities, and three during transportation to or from schools. Among the injured children, three had predominantly cerebral concussion, and Prevention of Injuries, Department of Hygiene and Epidemiology, Athens University, Medical School, 75, M Asias Str, Athens, 115 27, Greece E Petridou N Kouri K Revinthi

Y Skalkidis

Department of
Epidemiology,
Harvard School of
Public Health, 677
Huntington Avenue,
Boston, MA 02115,
USA
D Trichopoulos
D Tong
Correspondence to:
Dr D Trichopoulos.
Accepted for publication
February 1994

Multiple logistic regression-derived odds ratio estimates (and $95 \%$ confidence intervals) for school injury, associated with a series of family and socioeconomic variables

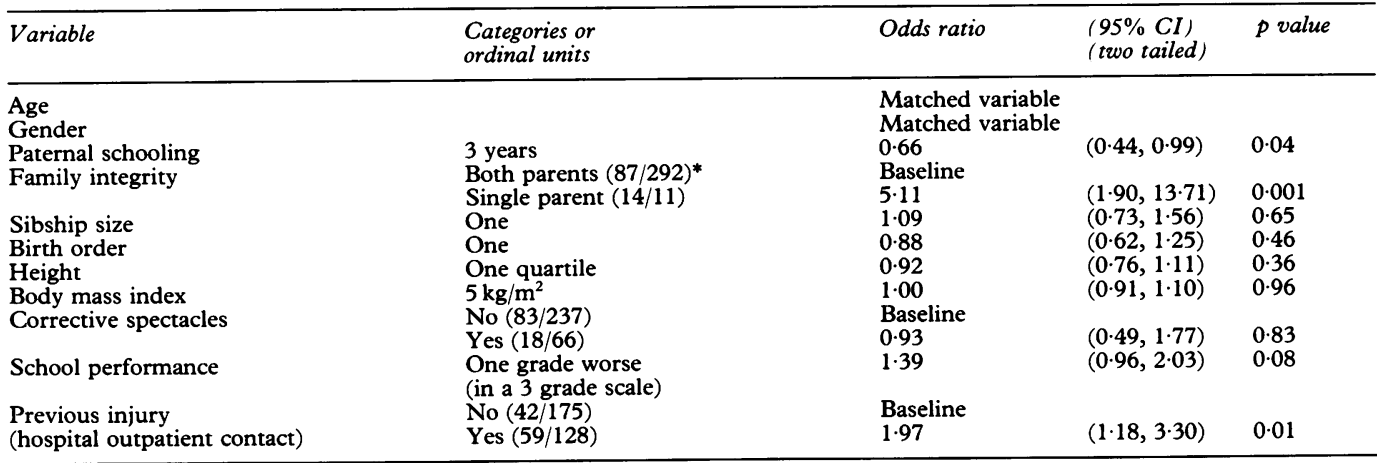

* Number of cases/controls. 